Research Article

\title{
Effective Absorption Capacity Examined by Isothermal Calorimetry: Effect of Pore Structure and Water-to-Cement Ratio
}

\author{
Joo-Ha Lee $\mathbb{D}^{1},{ }^{1}$ Do Guen Yoo $\left(\mathbb{D},{ }^{1}\right.$ and Bo Yeon Lee $\mathbb{D}^{2}$ \\ ${ }^{1}$ Department of Civil Engineering, The University of Suwon, Hwaseong-si 18323, Republic of Korea \\ ${ }^{2}$ Department of Architectural Engineering, The University of Suwon, Hwaseong-si 18323, Republic of Korea
}

Correspondence should be addressed to Bo Yeon Lee; bylee@suwon.ac.kr

Received 23 April 2020; Accepted 5 June 2020; Published 24 June 2020

Guest Editor: Young H. Kim

Copyright (c) 2020 Joo-Ha Lee et al. This is an open access article distributed under the Creative Commons Attribution License, which permits unrestricted use, distribution, and reproduction in any medium, provided the original work is properly cited.

\begin{abstract}
The accurate measurement of effective absorption capacity is crucial for highly absorptive materials when they are used within cement-based materials. In this study, a method for examining effective absorption capacity using isothermal calorimetry is reviewed and investigated in detail to accommodate different circumstances. Specifically, the effect of different pore structures and water-to-cement ratios in determining effective absorption capacity is experimentally examined using activated carbon fibre and powdered activated carbon. The results suggest that the method may be suitable for porous materials with micropores but not suitable for those with mesopores. Also, the results indicate that the effective absorption capacity value can change with the waterto-cement ratio used. These findings can be used to find the effective absorption capacity of highly absorptive materials more accurately using the isothermal calorimetry method.
\end{abstract}

\section{Introduction}

Cement-based materials such as concrete gain their strength through chemical reaction called hydration. Hydration occurs between cement and water, eventually forming hydration products or hardened cement paste. It is this hardened cement paste that gives concrete its major properties such as strength, porosity, shrinkage, and durability. When the water-to-cement ratio $(w / c)$ is increased, strength tends to decrease, porosity and shrinkage increase, and overall durability tends to decrease. Thus, it is crucial that precise amount of water be used in concrete mix design in order to achieve expected properties.

For concrete that is used for general purposes, mix proportion design to reach a target $w / c$ is not so challenging. However, special concretes have been developed and are being researched for specific purposes using various admixtures. When these admixtures are highly absorptive, modification to mix design should be performed; that is, water content should be increased in the amount that is absorbed by the material. Thus, absorption capacity of the material should be examined prior to carrying out mix design.
A good example of using highly absorptive material as an admixture to concrete is as an internal curing agent. The concept of internal curing of concrete emerged in the early 1990s [1] and has been consistently studied up until now. Internal curing is often referred to as "curing concrete from the inside out," by providing additional curing water throughout the concrete mixture. For the curing agent, highly absorptive materials are used, which are expected to act as internal reservoirs that release water during the cement hydration process. For example, highly absorptive materials such as lightweight aggregate (LWA) [2-4], recycled concrete aggregate [5], superabsorbent polymers (SAPs) [6-8], or cellulose fibres $[9,10]$ are mixed into the concrete. These internal curing agents are known to improve cement hydration, increase strength, reduce early cracking, etc. $[3,11]$. In addition, there is an evidence that highly absorptive fibres used for internal curing enhances early-age mechanical properties of cement-based materials. Jongvisuttisun and Kurtis suggested that hardwood pulp fibres mitigate early-age cracking of mortar by increasing early tensile capacity, reducing modulus, and improving postcracking toughness. These effects, combined with reductions 
in autogenous shrinkage due to the effect of internal curing, lead to superior early-age crack mitigation than that achieved through the use of superabsorbent polymer [12]. This indicates that internal curing agents in the form of fibre could have mechanical advantages in addition to known effects of internal curing.

As water is a key factor of cement hydration, internal curing has been often applied to concrete that requires a low water-to-cement ratio $(w / c)[3,8,13]$. The low water content could be linked to self-desiccation, autogenous shrinkage, and incomplete cement hydration, all of which can adversely affect the strength development and durability of concrete. Thus, the overall water content in concrete, both from mixing water and that retained in the internal curing agent, becomes more important for low $w / c$ concrete. In this context, it is crucial to first determine the accurate water absorption capacity of the internal curing materials. If the absorption capacity of a material is overpredicted, extra water would be released into cement paste at an early mixing stage. This would likely increase the $w / c$ of the cement paste and might eventually result in unexpected consequences such as lower strength $[10,14]$.

Despite the importance of accurate water absorption capacity measurement, there are no standards or recommendations that are suitable for fine, highly absorptive materials such as activated carbon whose absorption capacity reaches around 100 200\% of its mass. For example, ASTM C 128 describes a method to find the absorption of fine aggregate. However, this method is suitable to be applied for regular fine aggregate whose absorption capacity is generally less than $3 \%$ and is not suitable for highly absorptive material that has a high surface area and complex pore structure. Sometimes, tea-bag test is used for superabsorbent polymer $[7,15,16]$. This method, however, cannot effectively exclude water retained between and on particles or the water absorbed by the tea bag itself. Zhao et al. have proposed that interstitial water could affect absorption capacity of SAP [17]. Paper towel method (ASTM C 1761) can be used for lightweight aggregate, but it can only be applied to coarse aggregate and the measurement error appears to be relatively large [18].

Unlike the above methods that used water, Johansen et al. [10] suggested a method using isothermal calorimetry to examine the absorption capacity of an internal curing agent. The assessment occurs in cement-based materials, so pore solution rather than water is used. Also, compared to other methods that physically measure the amount of water absorbed, this method measures the heat of hydration of samples, which is a chemical indication of the rate of cement hydration. By comparing the early heat of hydration data of varying $w / c$ pastes with that of a paste containing an internal curing agent, the amount of water absorbed by the internal curing agent can be determined. The detailed methodology can be found in Johansen et al. [10]. Later, Castro et al. [19] used a similar approach to assess water absorbed by fine lightweight aggregate but by comparing total heat release.

Although the isothermal calorimetry method seems to overcome the shortcomings of the previous methods, several improvements can be made in order to apply it to different circumstances. First, the method assumes that the high surface area of the highly absorptive material does not alter the shape of rate of hydration curve. However, this may not hold true for some materials. That is, highly absorptive materials often have high pore volume and pore surface area. The surface area of the pores can act as nucleation sites for cement hydration that can potentially accelerate the cement hydration reaction. For instance, the addition of nanoparticles of $\mathrm{TiO}_{2}$, which have a high surface area, to cement paste accelerates cement hydration and alters the shape of rate of hydration curve [20]. Thus, materials that have high surface area due to pores could potentially affect the rate of cement hydration, which violates the main assumption of this method. When this happens, the shape of the rate of hydration curve is affected by both the surface area of the pores and the water content in the system, leading to misinterpretation of the results. Secondly, although it is an advantage to assess the absorption capacity within cementbased materials, these methods do not consider the effect of $w / c$ of the paste when examining the absorption capacity. For example, the material would absorb more pore solution at higher $w / c$ than at lower $w / c$, resulting in higher absorption capacity value.

This study aims to improve the method proposed by Johansen et al. [10] using multiple variables to accommodate different highly absorptive materials and different conditions. The detailed objectives of this study are to examine (1) the effect of different pore structures of the highly absorptive materials on the effective absorption capacity, and (2) the effect of $w / c$ used on the effective absorption capacity.

In this paper, the terminology "effective absorption capacity" (EAC) is used [21]. It is based on the assumption that an absorptive material would absorb pore solution only up to a state where moisture equilibrium is reached within the matrix. For example, high-strength concrete mixed at low $w / c$ would not have abundant pore solution available for internal curing agent to absorb, and some pores will remain empty. The EAC is defined as follows:

$$
\mathrm{EAC}=\frac{M_{\mathrm{EQ}}-M_{\mathrm{OD}}}{M_{\mathrm{OD}}} \times 100 \% .
$$

Here, $M_{\mathrm{OD}}$ represents mass of a material at oven-dry condition and $M_{\mathrm{EQ}}$ represents mass of a material at moisture equilibrium state. The EAC value can change when the moisture state changes. In comparison, conventionally used terminology "absorption capacity $(k)$ " is calculated using mass at saturated-surface-dry condition (SSD) rather than at moisture equilibrium state, representing a material's true capacity for water absorption. The absorption capacity is a fixed value. For example, when an absorptive material is mixed into cementitious materials, the moisture state between the material and the cement paste gets equilibrated in the early stage of hydration. If the material is at SSD, the material cannot retain the maximum amount of water but releases some until moisture equilibrium is reached with cement paste. This not only lowers the absorptive potential of the internal curing agent, but also increases the water content in the cementitious matrix unexpectedly, which 
might cause other serious problems. Thus, for the material that is expected to be used within another material, such as internal curing agents, the conventional definition of absorption capacity is not relevant. Rather, the amount of moisture that a material retains at moisture equilibrium state, as represented by EAC value, becomes more important. In most cases, the EAC value would be less than the conventional absorption capacity unless the base material has a relative humidity of $100 \%$. The EAC value would likely be dependent on the $w / c$ of the base material because cement paste with lower $w / c$ would draw more water from the absorptive material. This is investigated as the second objective of this study.

\section{Materials and Experimental Procedure}

2.1. Materials. The highly absorptive materials used for this study are activated carbon fibre (ACF) and powdered activated carbon (PAC). These materials have a similar composition, which is mostly carbon, and are processed to have small, low-volume pores. The major difference between the two in terms of absorption capacity is their pore structure. Thus, any influence of using materials with different compositions can be minimized, while the pore structure is the only variable. The ACF used was ACF-1603-10 (Kynol Activated Carbon Fiber, Gunei Chemicals). This type of ACF has been widely used for research. The average fibre length is $3 \mathrm{~mm}$ and fibre diameter is $10 \mu \mathrm{m}$, as stated by the manufacturer. This type of ACF is produced by carbonization and gasification of a phenolic resin precursor. The PAC used is produced from coal, passing \#325 mesh, as stated by the manufacturer. Particle size analysis was performed on PAC using ethanol as a dispersant (Mastersizer 2000, Malvern). The particle size distribution of PAC is shown in Figure 1.

Both materials were analysed by gas sorption analysis (3Flex, Micromeritics) to examine their pore characteristics. Pore size distribution was calculated by NLDFT method and is presented in Figure 2.

In Figure 2, the incremental pore volume is presented in terms of pore width. In the case of ACF, a single sharp peak was observed at pore width of $0.8-0.9 \mathrm{~nm}$ and most of the pore widths were below $1 \mathrm{~nm}$. Considering that microporous materials contain pores with diameters less than $2 \mathrm{~nm}$, ACF can be classified as microporous material. Compared to that, PAC showed a broader pore size distribution, beyond the limit of micropore range and extending to the mesopore range. The Brunauer-Emmett-Teller (BET) surface area was calculated to be $960 \mathrm{~m}^{2} / \mathrm{g}$ and $837 \mathrm{~m}^{2} / \mathrm{g}$ for ACF and PAC, respectively. Both of the materials were dried in an oven at $105^{\circ} \mathrm{C}$ for 24 hours to completely dry moisture in all the pores. Then they were stored separately in sealed containers until experiments were conducted.

The cement used in this study conforms to ASTM C 150 Type I Portland cement. The cement was analysed by X-ray fluorescence. The oxide composition of the cement analysed is presented in Table 1. Deionized water with $18.2 \mathrm{M} \Omega \mathrm{cm}$ resistivity was used as mixing water. Polycarboxylate superplasticizer (SP) was used in some of the pastes for workable consistency of the pastes.

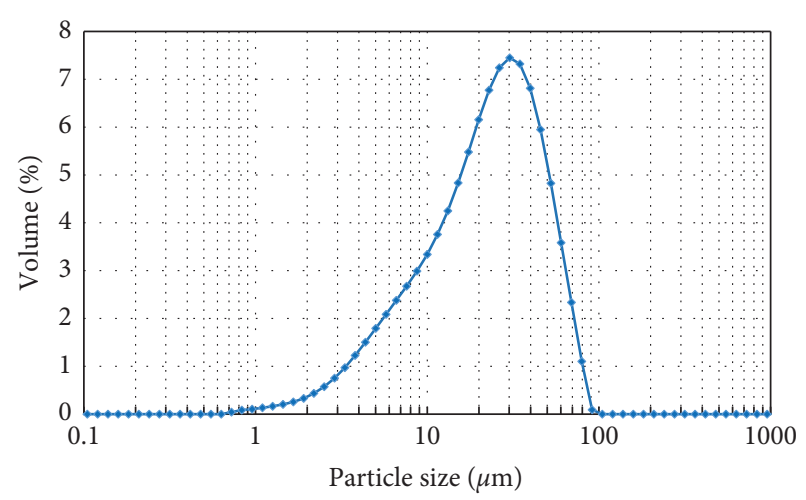

FIgURe 1: Particle size distribution of powdered activated carbon.

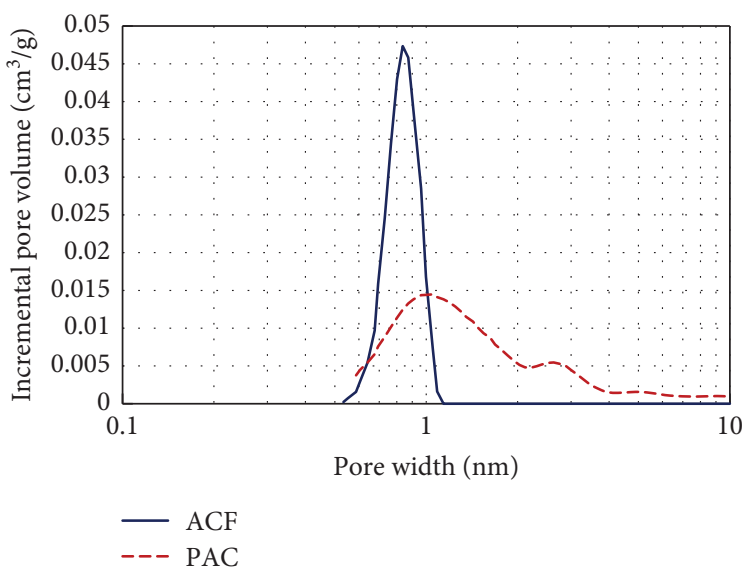

Figure 2: Pore size distribution of ACF and PAC.

TABLE 1: Chemical oxide analysis of cement.

\begin{tabular}{lc}
\hline Oxide/phase & $\mathrm{Wt} \%$ \\
\hline Silicon dioxide $\left(\mathrm{SiO}_{2}\right)$ & 21.17 \\
Aluminium oxide $\left(\mathrm{Al}_{2} \mathrm{O}_{3}\right)$ & 4.53 \\
Iron oxide $\left(\mathrm{Fe}_{2} \mathrm{O}_{3}\right)$ & 3.68 \\
Calcium oxide $(\mathrm{CaO})$ & 61.47 \\
Magnesium oxide $(\mathrm{MgO})$ & 4.16 \\
Titanium oxide $\left(\mathrm{TiO}_{2}\right)$ & 0.3 \\
Sodium oxide $\left(\mathrm{Na}_{2} \mathrm{O}\right)$ & 0.18 \\
Potassium oxide $\left(\mathrm{K}_{2} \mathrm{O}\right)$ & 0.9 \\
Manganic oxide $(\mathrm{MnO})$ & 0.12 \\
Phosphorus pentoxide $\left(\mathrm{P}_{2} \mathrm{O}_{5}\right)$ & 0.21 \\
Loss on ignition $(\mathrm{LOI})$ & 3.26 \\
Total & 99.98 \\
\hline
\end{tabular}

2.2. Mix Design. As stated in Introduction, this paper comprises two parts. The first part examines the influence of different pore structures in determining the effective absorption capacity. The second part investigates the effect of the water-to-cement ratio of the paste on the effective water absorption capacity.

2.2.1. Part 1: Investigation into Pore Structure. In the first part of the study, the two materials with different pore structures, ACF and PAC, were used to study the influence 
of their pore structure on EAC. Note that the pores of ACF are in the micropore range (pore diameter smaller than $2 \mathrm{~nm}$ ), while those of PAC are in the micropore range and mesopore range (pore diameter larger than $2 \mathrm{~nm}$ and smaller than $50 \mathrm{~nm}$ ). Cement pastes containing each of these materials, as well as neat cement paste (REF) as a reference sample, were prepared for isothermal calorimetry. The ACF and PAC were added at $1 \%$ of the mass of the cement. In this study, the amount of mixing water is divided into two classes. The amount of water used for cement hydration is referred to as "base water." The amount of water that should be added to accommodate the amount that is absorbed by either ACF or PAC is referred to as "additional water." For this part of the study, fixed $w / c$ was used at 0.30 , calculated using only base water. Iterations were performed by varying the amount of additional water because the EACs of these materials at this $w / c$ are not known yet. In order to achieve workable consistency, polycarboxylate superplasticizer was used. This type of superplasticizer is known to retard the cement hydration process [22], which affects the shape of the rate of hydration curve. Thus, the same dosage of superplasticizer was used for every comparative sample set, including the reference sample. For example, the same amount of superplasticizer was used for both ACF containing cement paste and the reference sample. This enabled a qualitative comparison within the same set of experiment. The mixing proportions of the first part are shown in Table 2.

2.2.2. Part 2: Investigation into $w / c$. For the second part examining the effect of different $w / c$ on the EAC, only activated carbon fibre was utilized. Three $w / c s$ were used: $0.25,0.30$, and 0.40 . The ACF was added at $1 \%$ of the mass of the cement. In this part, PAC was not used because the current methodology was found to be not suitable for a mesoporous material as will be demonstrated later. The mixing proportions of the samples were calculated in the same manner as in the first part of the study and are presented in Table 3.

2.3. Mixing. The mixing procedure was as follows. To prepare the samples, all materials and mixing equipment were equilibrated at $25 \pm 2^{\circ} \mathrm{C}$ for 24 hours before testing. Cement paste samples containing ACF or PAC were prepared along with the control ordinary Portland cement paste sample. For the samples that included ACF or PAC, the particles were submerged in a premeasured amount of total water (base water and additional water) for 5 minutes to give the materials some time to absorb water. In this step, superplasticizer was added. Cement was then added and mixed using a hand-held mixer.

2.4. Heat Release Measurement and EACCalculation. In both parts of this study, isothermal calorimetry was used (I-Cal 2000 HPC, Calmetrix) to measure the heat of cement hydration at $25^{\circ} \mathrm{C}$. The authors have performed multiple experiments with this equipment and obtained sufficiently reproducible results, verifying that it is suitable for this study. After mixing, $100 \pm 5 \mathrm{~g}$ of the samples were put in a plastic container and placed in the calorimeter less than 10 minutes after the mixing of water with cement. The calorimetry data of the initial 1 hour were excluded to allow the samples to become equilibrated within the instrument. Measurements were made up to the initial 24 hours from the start of mixing. The rate of hydration curves of these pastes will be compared to determine the EAC of the ACF and PAC mostly following the method proposed by Johansen et al. [10]. When the rate of the hydration curve for ACF or PAC paste coincides with that of REF at a certain value of additional water, it is inferred that the material has absorbed all of the additional water and the moisture equilibrium is reached within the matrix at $w / c=0.30$. Now, EAC can be calculated by dividing additional water by oven-dry mass of a material.

\section{Results and Discussion}

3.1. Effect of Pore Structure on the Effective Absorption Capacity. The first part of this study examined the effect of pore structure in determining the EAC of a porous material, when used within a cementitious matrix. In this part, the rate of hydration curves of ACF- and PAC-containing cement pastes are compared at $w / c=0.30$. The isothermal calorimetry results for the $\mathrm{ACF}$ and $\mathrm{PAC}$ are presented in Figures 3(a) and 3(b), respectively.

It is found in Figure 3(a) that the rate of hydration curve of a sample that was mixed with $150 \%$ additional water (ACF-150\%-30) almost overlapped with that of REF. This indicates that all the "additional water" stays within the pores of ACF during early hydration and that the cement only uses "base water" for hydration. This results in similar curve to that of the REF of the same $w / c$. It can be considered that the moisture equilibrium is reached between the ACF and the cement paste at $w / c=0.30$. In case of ACF-200\%-30, higher amount of additional water resulted in the shift of the curve to the right. The excess water is expected to increase the $w / c$ of the overall matrix, and moisture equilibrium would be reached at higher $w / c$. In general, higher $w / c$ slows the early hydration reaction, shifting the peak to the right $[10,19]$. On the other hand, the case of lower amount of additional water (ACF-120\%-30) resulted in the shift of the curve slightly to the left. Thus, the effective absorption capacity of the ACF is found to be $150 \%$ at this $w / c$ and addition rate used.

Here, it should be noted that the curves of ACF-150\%-30 and REF overlap very well despite ACF having a huge BET surface area. It was observed in another study that huge surface area of nano- $\mathrm{TiO}_{2}$ that had been added to cementitious materials altered the rate of hydration curve by acting as nucleation sites for cement hydration products [23]. For example, the addition of $5 \% \mathrm{TiO}_{2}$ to cement paste accelerated cement hydration and increased the peak rate of hydration. Compared to that, the higher BET surface area of ACF does not seem to affect the shape of the hydration curve. The authors presume that this is related to small pore radius of $\mathrm{ACF}$. There is a study suggesting that the hydration products cannot precipitate in pores with diameters smaller 
TABLE 2: Mixing proportions for part 1 (relative mass).

\begin{tabular}{|c|c|c|c|c|c|c|c|}
\hline \multirow{2}{*}{ Absorptive material } & \multirow{2}{*}{ Notation } & \multirow{2}{*}{ Cement } & \multirow{2}{*}{$\mathrm{ACF}$} & \multirow{2}{*}{ PAC } & \multicolumn{2}{|c|}{ Total water } & \multirow{2}{*}{ SP } \\
\hline & & & & & Base water & Additional water & \\
\hline \multirow{4}{*}{$\mathrm{ACF}$} & REF & 100 & 0 & 0 & 30 & 0.0 & 0.8 \\
\hline & ACF-120\%-30 & 100 & 1 & 0 & 30 & $1.2(120 \%)$ & 0.8 \\
\hline & ACF-150\%-30 & 100 & 1 & 0 & 30 & $1.5(150 \%)$ & 0.8 \\
\hline & ACF-200\%-30 & 100 & 1 & 0 & 30 & $2.0(200 \%)$ & 0.8 \\
\hline \multirow{4}{*}{ PAC } & REF & 100 & 0 & 0 & 30 & 0.0 & 1.0 \\
\hline & PAC- $160 \%-30$ & 100 & 0 & 1 & 30 & $1.6(160 \%)$ & 1.0 \\
\hline & PAC- $200 \%-30$ & 100 & 0 & 1 & 30 & $2.0(200 \%)$ & 1.0 \\
\hline & PAC- $240 \%-30$ & 100 & 0 & 1 & 30 & $2.4(240 \%)$ & 1.0 \\
\hline
\end{tabular}

TABLE 3: Mixing proportions for part 2 (relative mass).

\begin{tabular}{|c|c|c|c|c|c|}
\hline \multirow{2}{*}{ Notation } & \multirow{2}{*}{ Cement } & \multirow{2}{*}{$\mathrm{ACF}$} & \multicolumn{2}{|c|}{ Total water } & \multirow{2}{*}{ SP } \\
\hline & & & Base water & Additional water & \\
\hline REF & 100 & 0 & 25 & 0.0 & 1 \\
\hline $100 \%-25$ & 100 & 1 & 25 & $1.0(100 \%)$ & 1 \\
\hline $130 \%-25$ & 100 & 1 & 25 & $1.3(130 \%)$ & 1 \\
\hline $200 \%-25$ & 100 & 1 & 25 & $2.0(200 \%)$ & 1 \\
\hline REF & 100 & 0 & 30 & 0.0 & 0.8 \\
\hline $120 \%-30$ & 100 & 1 & 30 & $1.2(120 \%)$ & 0.8 \\
\hline $150 \%-30$ & 100 & 1 & 30 & $1.5(150 \%)$ & 0.8 \\
\hline $200 \%-30$ & 100 & 1 & 30 & $2.0(200 \%)$ & 0.8 \\
\hline REF & 100 & 0 & 40 & 0.0 & 0 \\
\hline $0 \%-40$ & 100 & 1 & 40 & $0.0(0 \%)$ & 0 \\
\hline $100 \%-40$ & 100 & 1 & 40 & $1.0(100 \%)$ & 0 \\
\hline $200 \%-40$ & 100 & 1 & 40 & $2.0(200 \%)$ & 0 \\
\hline
\end{tabular}

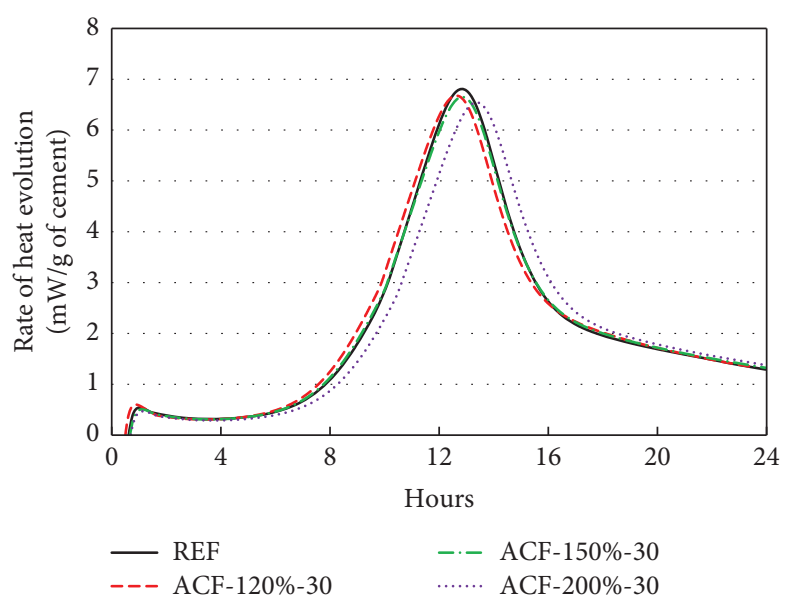

(a)

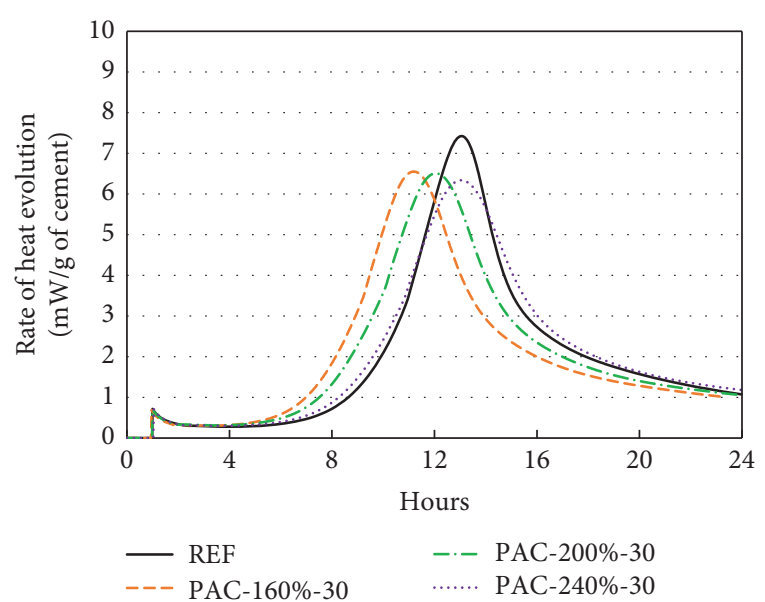

(b)

Figure 3: Rate of hydration curves of cement pastes: (a) REF- and ACF-containing cement pastes with 120\%, 150\%, and 200\% additional water; (b) REF- and PAC-containing cement pastes with 160\%, 200\%, and $240 \%$ additional water.

than about $2 \mathrm{~nm}$ [24]. Also, Kupwade-Patil et al. suggest that the size of a globule and its aggregates is expected to be in the range of $\sim 1 \mathrm{~nm}$ to $10 \mu \mathrm{m}$ at an early age of the cement hydration reaction, studied by Ultra-Small Angle X-Ray Scattering (USAXS) [25]. This indicates that hydration products would not likely precipitate in pores that are smaller than $1 \mathrm{~nm}$. Considering that the pore size of ACF is mostly less than $1 \mathrm{~nm}$, the hydration products would have not formed inside the micropores of ACF. In other words, the micropores act as water reservoirs but do not act as surface area for hydration product nucleation sites. As the micropores are the major cause of the huge BET surface area 


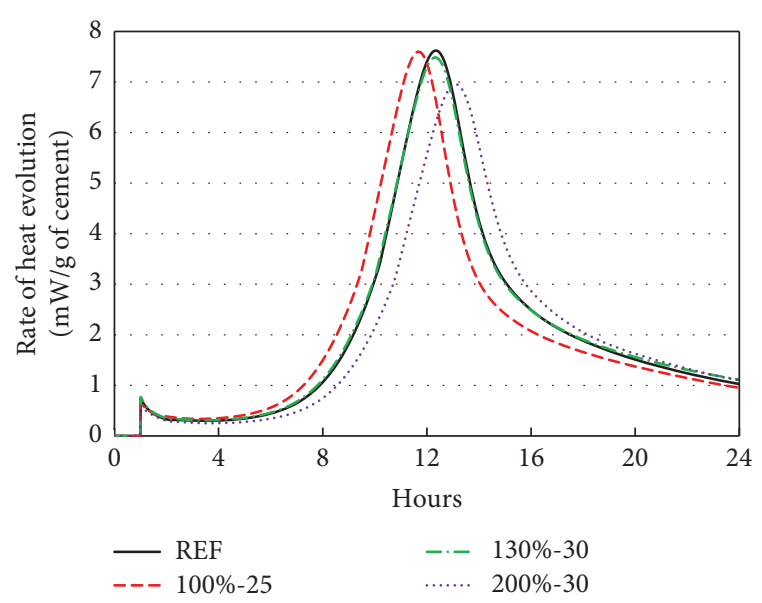

(a)

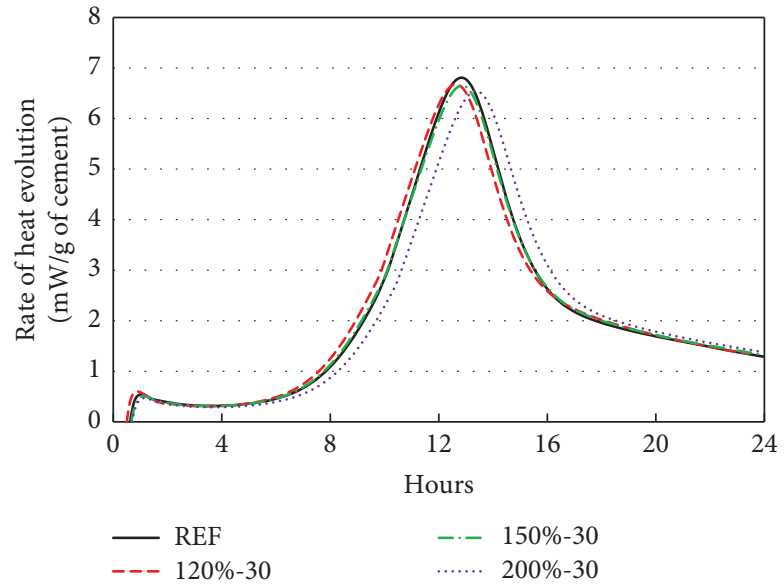

(b)

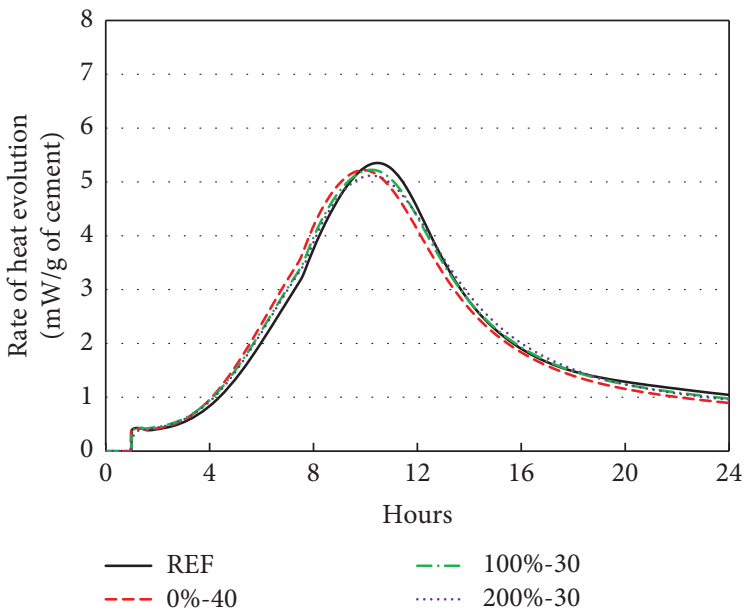

(c)

FIGURE 4: Rate of hydration curves of ACF-containing cement pastes: (a) $w / c=0.25$ with $100 \%, 130 \%$, and $200 \%$ additional water, (b) $w / c=0.30$ with $120 \%, 150 \%$, and $200 \%$ additional water, and (c) $w / c=0.40$ with $0 \%, 100 \%$, and $200 \%$ additional water.

of ACF, the BET value does not seem to have contributed to the change in the rate of the hydration process. Also, considering the micron scale size of the ACF, the authors presume that the outer surface area be too small to alter the shape of the rate of hydration curve.

On the other hand, in Figure 3(b), none of the rate of hydration curves of PAC-containing pastes overlap with that of REF for the amounts of additional water examined in this study. The curves shifted to the right with higher amounts of additional water as expected, implying that moisture equilibrium between PAC and cement paste were reached at higher $w / c$. However, the peak heights were lower than that of REF. The mismatch in the shape of the rate of hydration curves indicates that there have been changes in the cement hydration mechanism due to the addition of PAC. Considering that PAC does not take part in chemical hydration process, it is hypothesized that the surface area of PAC took part in the hydration reaction mechanism. As shown in Figure 2, the pore diameters of PAC are in the range of micropore and mesopore. This suggests that cement hydration products can crystallize and grow within the larger pores, meaning that the surface area of the pores could act as nucleation sites for cement products to hydrate, affecting the rate of cement hydration reaction. This is a distinctive difference between ACF and PAC. The mesopores of PAC seem to affect the rate of hydration curve not only by participating in moisture equilibrium but also by presumably providing extra surface area. Due to the added variable other than the $w / c$, the effective absorption capacity of PAC cannot be reasonably predicted using the isothermal calorimetry method.

3.2. Effect of $w / c$ on the Effective Absorption Capacity. In the second part, three water-to-cement ratios were compared at $0.25,0.30$, and 0.40 in order to examine whether the water content in cement paste affects the effective absorption capacity of an absorptive material. The isothermal calorimetry results for $w / c=0.25,0.30$, and 0.40 are presented in Figures 4(a)-4(c), respectively. Figure $4(\mathrm{~b})$ is reproduced from Figure 3(a) to better compare the trend between the three $w / c s$ examined. 
In Figure 4(a), it is found that the rate of hydration curve of the ACF-cement paste with $130 \%$ additional water $(130 \%$ 25 ) almost coincides with that of REF. Two curves match not only at the peak, but also in the acceleration and deceleration zones. This indicates that the cement paste, excluding ACF and water absorbed by the ACF, hydrates the same as REF. Thus, the effective absorption capacity of ACF can be concluded as $130 \%$ at this $w / c$ used. The additional water at $200 \%$ of the mass of ACF (200\%-25) resulted in the shift of the curve to the right compared to the REF curve. On the other hand, the additional water at $100 \%$ of the mass of ACF (100\%-25) resulted in the shift of the curve to the left compared to the REF curve. This trend is similar to Figure 3(a), where higher additional water was linked to moisture equilibrium at higher $w / c$. That is, higher $w / c$ and thus excess amounts of water tend to retard the hydration process and lower the peak rate of heat release, and vice versa, as stated in 3.1 .

Recalling that the EAC value was determined as $150 \%$ at $w / c=0.30$ (Figure 3(a)), the one obtained here at $w / c=0.25$ shows a lower value of $130 \%$. This implies that the effective absorption capacity of a material can be different at different $w / c$ used. This can be explained by the equilibrium of moisture state between cement paste and the absorptive material. At higher $w / c$, water is more abundant throughout the cement paste. The absorptive material should retain more water to maintain moisture equilibrium with the cement paste. Thus, the effective absorption capacity tends to increase. This suggests that the EAC value can change according to $w / c$ used. When using the isothermal calorimetry method to find the effective absorption capacity of an absorptive material, the most accurate result can be acquired when the $w / c$ used for isothermal calorimetry is the same as the $w / c$ that will be used for the end purpose.

Comparing Figures 4(a)-4(c), the curves are more congested around REF curve as the $w / c$ increases. For example, curves of 100\%-25 and 200\%-25 are clearly separated from that of REF (Figure 4(a)) but curves of 100\%-40 and 200\%-40 almost overlap with that of REF (Figure $4(\mathrm{c})$ ). In fact, the rates of hydration curves for the $w / c=0.4$ case do not show meaningful differences, and it was not possible to find the EAC. It is obvious that the lower $w / c$ allows for better examination of the EAC. This is related to the amount of water that is needed to fully complete hydration reaction of cement, known approximately at $w / c=0.30-0.35$. At low $w / c$, cement is in need of water for hydration. So small change in water content is directly related to hydration reaction. At high $w / c$, on the other hand, cement already has water for hydration; thus small change in water content does not effectively alter the hydration curve. It is recommended that the $w / c$ be less than 0.40 to be able to examine the EAC using the isothermal calorimetry method.

\section{Conclusions}

In this study, isothermal calorimetry method was used to determine the effective absorption capacity of absorptive materials. Several factors were investigated that could affect the EAC value. It was found that the effective absorption capacity of a material that has micropores (ACF) can be determined by the isothermal calorimetry method. However, the effective absorption capacity of a material that has both micropores and mesopores (PAC) was not successfully predicted. It is presumed that surface area of mesopores affects the shape of the rate of cement hydration. This could interfere with the effect of moisture equilibrium, leading to improper interpretation of the effective absorption capacity. Also, it was found that lower $w / c$ is related to lower EAC when this method is used. At lower $w / c$, absorptive material would absorb less water and reach moisture equilibrium at lower $w / c$. It is recommended that the $w / c$ less than 0.40 be used, so that rates of hydration curves are clearly distinguished and more accurate EAC can be obtained.

\section{Data Availability}

The data used to support the findings of this study are available from the corresponding author upon request.

\section{Conflicts of Interest}

The authors declare that there are no conflicts of interest regarding the publication of this paper.

\section{Acknowledgments}

This study was supported by a research grant from the University of Suwon in 2017.

\section{References}

[1] R. Philleo, "Concrete science and reality," Materials Science of Concrete, pp. 1-8, American Ceramic Society, Westerville, OH, USA, 1991.

[2] D. P. Bentz and K. A. Snyder, "Protected paste volume in concrete: extension to internal curing using saturated lightweight fine aggregate," Cement and Concrete Research, vol. 29, no. 11, pp. 1863-1867, 1999.

[3] D. Cusson and T. Hoogeveen, "Internal curing of high-performance concrete with pre-soaked fine lightweight aggregate for prevention of autogenous shrinkage cracking," Cement and Concrete Research, vol. 38, no. 6, pp. 757-765, 2008.

[4] A. Bentur, S.-I. Igarashi, and K. Kovler, "Prevention of autogenous shrinkage in high-strength concrete by internal curing using wet lightweight aggregates," Cement and Concrete Research, vol. 31, no. 11, pp. 1587-1591, 2001.

[5] S. T. Yildirim, C. Meyer, and S. Herfellner, "Effects of internal curing on the strength, drying shrinkage and freeze-thaw resistance of concrete containing recycled concrete aggregates," Construction and Building Materials, vol. 91, pp. 288-296, 2015.

[6] S.-I. Igarashi and A. Watanabe, "Experimental study on prevention of autogenous deformation by internal curing using super-absorbent polymer particles," in Proceedings of the International RILEM Conference on Volume Changes of Hardening Concrete: Testing and Mitigation, Lyngby, Denmark, August 2006.

[7] S.-H. Kang, J. Moon, and S.-G. Hong, "Effect of internal curing by super-absorbent polymer (SAP) on hydration, autogenous shrinkage, durability and mechanical 
characteristics of ultra-high performance concrete (UHPC)," Journal of the Korea Concrete Institute, vol. 28, no. 3, pp. 317-328, 2016.

[8] J. Justs, M. Wyrzykowski, D. Bajare, and P. Lura, "Internal curing by superabsorbent polymers in ultra-high performance concrete," Cement and Concrete Research, vol. 76, pp. 82-90, 2015.

[9] P. Jongvisuttisun, C. Negrello, and K. E. Kurtis, "Effect of processing variables on efficiency of eucalyptus pulps for internal curing," Cement and Concrete Composites, vol. 37, pp. 126-135, 2013.

[10] N. A. Johansen, M. J. Millard, A. Mezencevova, V. Y. Garas, and K. E. Kurtis, "New method for determination of absorption capacity of internal curing agents," Cement and Concrete Research, vol. 39, no. 1, pp. 65-68, 2009.

[11] M. Suzuki, M. S. Meddah, and R. Sato, "Use of porous ceramic waste aggregates for internal curing of high-performance concrete," Cement and Concrete Research, vol. 39, no. 5, pp. 373-381, 2009.

[12] P. Jongvisuttisun and K. E. Kurtis, “The role of hardwood pulp fibers in mitigation of early-age cracking," Cement and Concrete Composites, vol. 57, pp. 84-93, 2015.

[13] O. M. Jensen and P. Lura, "Techniques and materials for internal water curing of concrete," Materials and Structures, vol. 39, no. 9, pp. 817-825, 2006.

[14] T. Hammer, "High strength LWA concrete with silica fume effect of water content in the LWA on mechanical properties," Supplementary Papers in the Fourth CANMET/ACI International Conference on Fly Ash, Silica Fume, Slag, and Natural Pozzolans in Concrete: Istanbul, Turkey, 1992, CANMET/ACI, Indianapolis, IN, USA, 1992.

[15] S.-H. Kang, S.-G. Hong, and J. Moon, “Absorption kinetics of superabsorbent polymers (SAP) in various cement-based solutions," Cement and Concrete Research, vol. 97, pp. 73-83, 2017.

[16] C. Schröfl, V. Mechtcherine, and M. Gorges, "Relation between the molecular structure and the efficiency of superabsorbent polymers (SAP) as concrete admixture to mitigate autogenous shrinkage," Cement and Concrete Research, vol. 42, no. 6, pp. 865-873, 2012.

[17] S. Zhao, O. M. Jensen, and M. T. Hasholt, "Measuring absorption of superabsorbent polymers in cementitious environments," Materials and Structures, vol. 53, no. 1, p. 11, 2020.

[18] E. Albert, I. V. Miller, R. Spragg et al., "Determining the moisture content of pre-wetted lightweight aggregate: assessing the variability of the paper towel and centrifuge methods," in Proceedings of the 4th International Conference on the Durability of Concrete Structures, West Lafayette, IN, USA, July 2014.

[19] J. Castro, I. D. L. Varga, and J. Weiss, "Using isothermal calorimetry to assess the water absorbed by fine LWA during mixing," Journal of Materials in Civil Engineering, vol. 24, no. 8, pp. 996-1005, 2012.

[20] B. Y. Lee, A. R. Jayapalan, and K. E. Kurtis, "Effects of nano$\mathrm{TiO}_{2}$ on properties of cement-based materials," Magazine of Concrete Research, vol. 65, no. 21, pp. 1293-1302, 2013.

[21] B. Y. Lee, "Effective absorption capacity of highly absorptive materials using isothermal calorimetry, considering the effect of specific surface area," Journal of the Architectural Institute of Korea Structure \& Construction, vol. 34, no. 2, pp. 49-56, 2018.

[22] F. Puertas, H. Santos, M. Palacios, and S. Martínez-Ramírez, "Polycarboxylate superplasticiser admixtures: effect on hydration, microstructure and rheological behaviour in cement pastes," Advances in Cement Research, vol. 17, no. 2, pp. 77-89, 2005.

[23] B. Y. Lee and K. E. Kurtis, "Influence of $\mathrm{TiO}_{2}$ nanoparticles on early $\mathrm{C}_{3} \mathrm{~S}$ hydration," Journal of the American Ceramic Society, vol. 93, no. 10, pp. 3399-3405, 2010.

[24] K. K. Aligizaki, Pore Structure of Cement-Based Materials: Testing, Interpretation and Requirements, Crc Press, Boca Raton, FL, USA, 2005.

[25] K. Kupwade-Patil, S. Chin, J. Ilavsky, R. N. Andrews, A. Bumajdad, and O. Büyüköztürk, "Hydration kinetics and morphology of cement pastes with pozzolanic volcanic ash studied via synchrotron-based techniques," Journal of Materials Science, vol. 53, no. 3, pp. 1743-1757, 2018. 